\title{
Active Intracellular Domain of Notch Enhances Transcriptional Activation of CCAAT/Enhancer Binding Protein $\beta$ on a Rat Pregnancy-Specific Glycoprotein Gene $^{\dagger}$
}

\author{
Hungwen Chen, ${ }^{*}, \S$ Yichuen Chong, ${ }^{\S}$ and Chia-Lin Liu ${ }^{\S}$ \\ Institute of Biological Chemistry, Academia Sinica, Nankang, Taipei 115, Taiwan, and Graduate Institute of Biochemical \\ Sciences, National Taiwan University, Taipei 10098, Taiwan
}

Received August 2, 1999; Revised Manuscript Received October 27, 1999

\begin{abstract}
Pregnancy-specific glycoproteins (PSGs) are primarily expressed in the placenta and become the major glycoproteins at term. To understand the regulation of $P S G$ expression, we characterized the promoter elements of a rodent $P S G$ gene, $r n C G M 3$, and delineated three nuclear protein binding sites: FPI, -II, and -III in the 5'-flanking region of the gene. The FPII-binding factor is shown to be C/EBP $\beta$, which positively regulates rnCGM3 expression [Chen, H., et al. (1995) DNA Cell Biol. 14, 681-688]. In the current study, we used the yeast one-hybrid system to isolate transcription factors binding to the FPIII site and demonstrated that a rodent $\mathrm{J} \kappa$ recombination signal sequence binding protein, $\mathrm{rRBPJ} \kappa-2 \mathrm{~N}$, bound to the FPIII site. Electrophoretic mobility shift assay with rat placental nuclear proteins revealed a constitutive occupancy of the FPIII site by $\mathrm{RBPJ} \kappa$. By transient expression analyses, we demonstrated that $\mathrm{rRBPJ} \kappa-2 \mathrm{~N}$ repressed the expression from an FPIII-driven SV40 promoter. However, this repression effect was counteracted by the active intracellular domain of Notch (NotchIC). Using the native $r n C G M 3$ promoter construct, we demonstrated that the promoter activity stimulated by $\mathrm{C} / \mathrm{EBP} \beta$ was also repressed by $\mathrm{rRBPJ} \kappa-2 \mathrm{~N}$ but enhanced by NotchIC. Additionally, we found that NotchIC can stimulate expression through another $\mathrm{RBPJ} \kappa$ site within the FPI site. A functional interaction between factors binding to the FPI, FPII, and FPIII sites is proposed.
\end{abstract}

Many proteins, steroid hormones, cytokines, and growth factors are released from placenta to the maternal circulation in order to maintain pregnancy and fetal development. Pregnancy-specific glycoproteins (PSGs) are a family of glycoproteins synthesized by the syncytiotrophoblast in placenta (1). Human PSGs are consistently detectable in the maternal serum during the first 2-3 weeks of pregnancy. The level of PSGs in maternal circulation increases exponentially to reach $200-400 \mu \mathrm{g} / \mathrm{mL}$ and becomes the most abundant placental proteins at term (2). Although the exact function(s) of PSGs is still not known, low levels of PSGs are associated with poor pregnancy outcomes $(3-6)$. Furthermore, antisera against PSGs have been shown to induce abortions in mice and monkeys $(7,8)$. Putative PSG receptors

\footnotetext{
This work was supported by grants (to H.C.) from the National Science Council (Grant 88-2311-B-001-115) and Academia Sinica of Taiwan.

* Correspondence should be addressed to this author: Tel 011-8862-27855696, ext 6090; Fax 011-886-2-27889759; E-mail hwchen@gate.sinica.edu.tw.

Institute of Biological Chemistry, Academia Sinica.

$\S$ Graduate Institue of Biochemical Sciences, National Taiwan University.

${ }^{1}$ Abbreviations: PSG, pregnancy-specific glycoprotein; $\mathrm{C} / \mathrm{EBP} \beta$, CCAAT/enhancer binding protein $\beta ; \operatorname{RBPJ}_{\kappa}, \mathrm{J}_{\kappa}$ recombination signal sequence binding protein; NotchIC, intracellular domain of Notch; 3-AT, 3-aminotriazole; EMSA, electrophoretic mobility shift assay; AD, activation domain; $E(s p l)$, Enhancer of split; MHC, major histocompatibility complex; NLS, nuclear localization signal; EBV, EpsteinBarr virus; $S u(H)$, Suppressor of Hairless; EBNA2, Epstein-Barr virus nuclear antigen 2; CIR, CBF1 interacting corepressor, HDAC, histone deacetylase; HES-1, Hairy enhancer of split; TCR, T-cell receptor.
}

have also been identified on monocytic cell lines, suggesting a possible role of PSGs in regulating the maternal immune system during pregnancy (9).

As a model to understand human $P S G$ expression and protein functions, several rodent or murine homologues of human $P S G$ genes have been isolated and characterized. For example, the expression of a rodent $P S G$ gene, $r n C G M 1$, was detected in the giant cell/spongiotrophoblast in rat placenta (10). We have also characterized two other rodent $P S G$ genes, $r n C G M 6$ and $r n C G M 3$, and demonstrated that both are primarily expressed in rat placenta $(11,12)$. Kromer et al. (13) studied the expression kinetics of three murine PSG genes, Cea2, Cea3, and Cea4, during placental development and revealed that expression starts at the embryonic stage E12.5 and reaches the maximum steady-state level between E15.5 and E17.5. They also detected an exclusive expression of PSG transcripts in the spongiotrophoblast of the placenta at E17.5.

In an effort to study the molecular mechanisms underlying the placenta-specific expression of $P S G$ genes, in previous studies we have sequenced the $5^{\prime}$-flanking region of $r n C G M 3$ and showed that a TATA box, CATAAA, is located at the nucleotides -226 to -221 region upstream of the translation start site (11). We also analyzed the promoter of $r n C G M 3$ and delineated two promoter elements, PI and PII, that are located upstream and downstream of the transcription start site, respectively (11). Based on DNase I footprinting analyses, two nuclear protein binding sites at nucleotides -311 to -290 (PISI) and -257 to -239 (PISII) in the PI 
A

\section{Rat PSG gene: $r n C G M 3$}
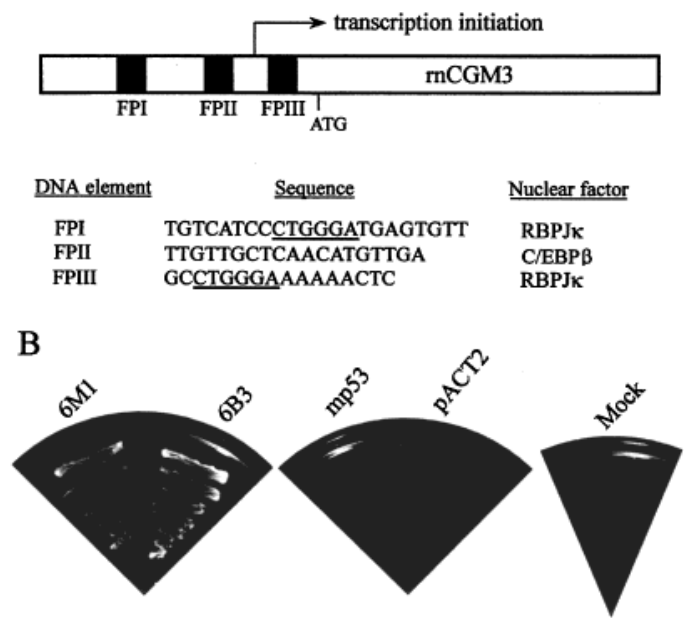

FiguRE 1: (A) Schematic representation of the rodent PSG gene, $r n C G M 3$. The three DNase I-protected regions in the promoter of rnCGM3 are depicted as solid boxes and denoted as FPI (nucleotides -311/-290), FPII (nucleotides -257/-239), and FPIII (nucleotides -108/-93), respectively. An arrow denotes the transcription initiation site located at nucleotide -197 upstream of the translation start site (denoted as ATG). The lower part of the panel shows the sense-strand sequence of each DNase I-protected region in the $5^{\prime}$ to $3^{\prime}$ direction and the nuclear factor binding to each region. The core binding sequences for $\mathrm{RBPJ} \kappa$ in FPI and FPIII sites are underlined. (B) In vivo interaction of candidate proteins with the FPIII element. Clones $6 \mathrm{~B} 3$ and $6 \mathrm{M} 1$ encoding GAL4-RBPJ $\kappa$ fusion proteins were introduced into the yeast strain YM4271FPIII. Cells were plated on synthetic medium minus histidine and leucine and containing $30 \mathrm{mM} 3-\mathrm{AT}$. As controls, yeast cells were also transformed with TE $(10 \mathrm{mM}$ Tris- $\mathrm{HCl}, \mathrm{pH}$ 8.0, and $1 \mathrm{mM}$ EDTA) solution (mock), the mouse p53 (mp53), or the parental plasmid (pACT2).

element and one binding site at nucleotides -108 to -93 (PIISIII) in the PII element (see Figure 1A) were further identified (11). For simplicity, we will call PISI, PISII, and PIISIII as FPI, FPII, and FPIII, respectively, in this report. It has been shown that the factor binding to the FPII site is $\mathrm{C} / \mathrm{EBP} \beta$ (14), a member of the bZIP-class of transcription factors that contain a basic DNA-binding region adjacent to a leucine zipper dimerization domain.

Because $P S G$ is specifically expressed in placenta and the level of PSG increases exponentially during placental development, we speculate that additional transcription factors, in response to environmental cues such as hormones, cytokines, and growth factors, are involved in the upregulation of $P S G$ expression. In the present study, we used the yeast one-hybrid system (15) to perform an in vivo screening of a placental cDNA library to isolate nuclear factors binding to the FPIII site. We show that the rodent $J_{\kappa}$ recombination signal sequence binding protein $(\mathrm{RBPJ} \kappa) \mathrm{rRBPJ} \kappa-2 \mathrm{~N}$ binds to the FPIII site. We further demonstrate that $\operatorname{rRBPJ} \kappa-2 \mathrm{~N}$ repressed the expression of an FPIII-driven promoter construct. We also show that the active intracellular domain of Notch (NotchIC) counteracted the repressor activities of $\operatorname{rRBPJ} \kappa-2 \mathrm{~N}$. In the native context of $r n C G M 3$ promoter, the promoter activity stimulated by $\mathrm{C} / \mathrm{EBP} \beta$ was also repressed by $\operatorname{rRBPJ} \kappa-2 \mathrm{~N}$ but enhanced by NotchIC. Additionally, we found that NotchIC stimulated C/EBP $\beta$-dependent expression through another $\mathrm{RBPJ}_{\kappa}$ site within the FPI site using an FPIII-deleted native promoter construct. Our data suggest that the placenta-specific expression of $r n C G M 3$ may be connected to C/EBP $\beta$ and the Notch signaling pathway.

\section{MATERIALS AND METHODS}

Library Screening and Characterization of cDNA Clones. The yeast one-hybrid system was purchased from Clontech (Palo Alto, CA). Yeast cells were transformed by standard procedures using the lithium acetate method (16). Six tandem copies of the FPIII element (5'-GCCTGGGAAAAAACTC$3^{\prime}$ ), generated by self-ligation using T4 ligase, were placed upstream of the minimal promoter of the yeast HIS3 gene in vector pHISi-1 to generate the target reporter plasmid, $\mathrm{p}$ (FPIII) ${ }_{6}$ HIS3. Yeast strain YM4271 (MATa ura3-52 his3200 ade2-101 lys2-801 leu2-3 112 trp1-903 tyrl-501) was transformed with $2 \mu \mathrm{g}$ of linearized p(FPIII) ${ }_{6} \mathrm{HIS} 3$ and then plated onto a synthetic medium without histidine (SD/-His) to select for positive reporter strains. One of the strains, YM4271FPIII, has a low level of HIS3 activity and did not replicate on SD/-His plates supplemented with $30 \mathrm{mM}$ 3 -aminotriazole (3-AT), a competitive inhibitor of the yeast HIS3 protein. For yeast one-hybrid screening, $300 \mathrm{~mL}$ of YM4271FPIII cells were grown to mid-log phase in YPD medium. Cells were transformed with $20 \mu \mathrm{g}$ of a pACT2 human placental cDNA library (a GAL4 activation domain fusion library; Clontech) and plated onto a synthetic medium minus histidine and leucine and containing $30 \mathrm{mM} 3$-AT. Approximately $5 \times 10^{6}$ yeast colonies were screened. Positive colonies were purified after two more rounds of streaking on selection plates. The pACT2 plasmids were rescued from the positive clones, retransformed into Escherichia coli strain HB101, and purified for sequencing.

Plasmid Constructs. For the C/EBP $\beta$ expression plasmid pCMVC/EBP $\beta$, a BamHI fragment excised from pMEXCRP2 (17) was blunt-ended and cloned into pRcCMV (Invitrogen, Carlsbad, CA). The rodent $R B P J \kappa, r R B P J \kappa-2 N$, was isolated from a rat placental $\lambda$ gt 10 cDNA library using the human $R B P J \kappa$ cDNA probe obtained from the yeast onehybrid screen. The coding region of $r R B P J \kappa-2 N$ was amplified by polymerase chain reaction (PCR) with the $P f u$ DNA polymerase (Stratagene, La Jolla, CA) and cloned into pRcCMV to make the pCMVrRBPJ $\kappa$ - $2 \mathrm{~N}$ plasmid. The murine Notchl expression plasmid mNotchIC (18) was kindly provided by Dr. R. Kopan (Washington University, St. Louis, MO).

The plasmid $\mathrm{p}(\mathrm{FPIII})_{6} \mathrm{SV} 40 \mathrm{CAT}$ contains six FPIII sites fused to the SV40 promoter element and the bacterial CAT gene coding sequence. To make constructs containing multimerized mutant FPIII sites, five copies of FPIIIM34 (5'-GCTAGGGAAAAAACTC-3') and four copies of FPIIIM56 (5'-GCCTCCGAAAAAACTC-3') oligonucleotides were inserted in front of the SV40 promoter element to generate the p(FPIIIM34) 5 SV40CAT and p(FPIIIM56) ${ }_{4}$ SV40CAT reporter plasmids, respectively. Similarly, six copies of FPI (5'-TGTCATCCCTGGGATGAGTGTT-3') and FPIM34A (5'-TGTCATCCAGGGGATGAGTGTT-3') oligonucleotides were inserted in front of the SV40 promoter element to generate the $\mathrm{p}(\mathrm{FPI})_{6} \mathrm{SV} 40 \mathrm{CAT}$ and $\mathrm{p}(\mathrm{FPIM} 34 \mathrm{~A})_{6^{-}}$ SV40CAT reporter plasmids, respectively. The $r n C G M 3$ promoter construct pCGM3A containing all three FP sites was generated by inserting the $r n C G M 3$ promoter region of nucleotides -326 to -33 relative to the translation start site 


\begin{tabular}{|c|c|c|}
\hline & FPIII mutant oligonucleotide & $\begin{array}{l}\text { binding to } \\
\operatorname{rRBPJ}_{\kappa}-2 \mathrm{~N}\end{array}$ \\
\hline Wt & 5'-GCCTGGGAAAAAACTC-3' & + \\
\hline M34 & 5'-GCtaGGGAAAAAACTC-3' & - \\
\hline M34A & $5^{\prime}$-GCagGGGAAAAAACTC- $3^{\prime}$ & - \\
\hline M56 & $5^{\prime}$-GC $\overline{C T c c G A A A A A A C T C}-3^{\prime}$ & - \\
\hline M78 & 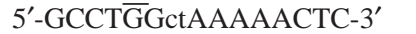 & - \\
\hline M910 & 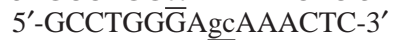 & + \\
\hline M1112 & 5'-GCCTGGGA AAggACTC-3' & + \\
\hline M1314 & 5'-GCCTGGGAAA AAtgTC-3' & + \\
\hline
\end{tabular}

${ }^{a}$ EMSA was performed with labeled FPIII probe and the in vitrotranslated $\operatorname{rRBPJ} \kappa-2 \mathrm{~N}$. Individual mutant oligonucleotides were included at 100 -fold molar excess as unlabeled competitors.

in front of the luciferase gene of the pGL3-Basic plasmid (Promega, Madison, WI). The pCGM3A- $\triangle$ FPIII construct is identical to pCGM3A except that the FPIII site is deleted. The pCGM3B construct contains the rnCGM3 promoter region of nucleotides -283 to -33 , which includes the FPII and III sites. The pCGM3B-FPIIIM34A construct is identical to pCGM3B except it contains the M34A mutation in the FPIII site. The pCGM3A-FPI\&IIIM34A construct is identical to pCGM3A except it contains the M34A mutation in FPI (5'-TGTCATCCAGGGGATGAGTGTT-3') and the M34A mutation in FPIII (5'-GCAGGGGAAAAAACTC-3'). All constructs were verified by DNA sequencing.

Electrophoretic Mobility Shift Assay. For electrophoretic mobility shift assay (EMSA), nuclear extracts of rat placentas were prepared as described by Ohlsson and Edlund (19). In vitro transcription/translation of $r R B P J \kappa-2 N$ cDNA was performed with the TNT-coupled wheat germ extract system (Promega). End-labeled oligonucleotide FPIII probes [1 ng; $\left.(0.5-1) \times 10^{5} \mathrm{cpm}\right]$ were incubated in the binding reaction buffer (10 mM Tris-HCl, pH 7.5, $50 \mathrm{mM} \mathrm{NaCl}, 0.05 \%$ NP$40,0.5 \mathrm{mM}$ DTT, and $10 \%$ glycerol) containing $1 \mu \mathrm{g}$ of poly $(\mathrm{dI}-\mathrm{dC})$ and $2 \mu \mathrm{g}$ of placental nuclear extracts or $1 \mu \mathrm{L}$ of in vitro-translated proteins. After incubation at room temperature for $20 \mathrm{~min}$, the reaction mixtures were analyzed by electrophoresis on 5\% nondenaturing polyacrylamide gels. For competition experiments, the unlabeled oligonucleotides were used at a 100-fold molar excess and incubated with the in vitro-translated protein or nuclear extracts for $20 \mathrm{~min}$ on ice before addition of radiolabeled probes. For proteolyticclipping EMSA (20), the protein-DNA complex was incubated with indicated amounts of proteases on ice for 10 min and the reaction mixtures were immediately analyzed as described above.

Oligonucleotides used in EMSA were m8, 5'- GGGCACTGTGGGAACGGAAA; KBF, 5'-TAGAAGATGGGGAATCCCCA; $\beta 2 \mathrm{~m}, 5^{\prime}$-AGATGATGGGAAAGTCCCTT; and $\kappa$ light chain, 5'-CAGAGGGGACTTTCCGAGAG; FPIII and its mutant oligonucleotides were as listed in Table 1.

Cell Culture, Transfection, and Reporter Gene Assays. COS- 1 and COS-7 cells were grown at $37^{\circ} \mathrm{C}$ in HEPESbuffered Dulbecco's modified minimal essential medium supplemented with $4 \%$ fetal bovine serum, $100 \mu \mathrm{g} / \mathrm{mL}$ streptomycin, and 100 units $/ \mathrm{mL}$ penicillin. Cells in $30-\mathrm{mm}$ culture plates were incubated with $2 \mathrm{~mL}$ of a calcium phosphate-DNA coprecipitate containing $3 \mu \mathrm{g}$ of reporter plasmids and various amounts of expression plasmids (as indicated in figure legends) as well as an pRcCMV empty vector to maintain a constant amount of DNA in each transfection assay. To correct for transfection efficiency, 0.5 $\mu \mathrm{g}$ of pRSV $\beta$ gal was used as an internal control. Cells were harvested in the reporter lysis buffer (Promega) $48 \mathrm{~h}$ after transfection. CAT activity was assayed by incubating total cellular proteins in the reporter lysis buffer plus $4 \mathrm{mM}$ acetyl coenzyme A and $0.1 \mu \mathrm{Ci}$ of $\left[{ }^{14} \mathrm{C}\right]$ chloramphenicol (2l). The assay was routinely run for $1 \mathrm{~h}$ with the amount of extracts required to convert $0.5-50 \%$ of the substrate to the acetylated forms. Assays outside this range were repeated with the appropriate amount of extracts. The acetylated compounds were separated from chloramphenicol by thin-layer chromatography (95\% chloroform-5\% methanol v/v) on silica gel 60 (Merck) and quantitated by the bio-imaging analyzer, BAS-1500 (Fujifilm, Japan). Luciferase activity was assayed with the luciferase assay system (Promega). The reaction was initiated by adding luciferin, and the light emission was monitored by a luminometer (Lumat LB 9501, EG \& G Berthold, Germany). Specific CAT and luciferase activities were normalized by the internal $\beta$-galactosidase activity. $\beta$-Galactosidase enzymatic activities were assayed as described (16). Protein concentrations were measured with the BCA protein assay kit (Pierce, Rockford, IL).

\section{RESULTS}

Isolation and Characterization of the FPIII-Binding Factors. To identify nuclear factors binding to the FPIII site of the $r n C G M 3$ gene (Figure 1A), we performed an in vivo screening of a pACT2 human placental cDNA library using the yeast one-hybrid system. A human placental cDNA library was used because the expression patterns of the human and rat PSG genes are very similar and a human placental cDNA library is commercially available. Approximately $5 \times 10^{6}$ yeast colonies were screened and 10 positive clones were further characterized. Four of them encoded $\mathrm{RBPJ} \kappa$ initiating at different nucleotides in the exon 2 region of the human $R B P J \kappa$ gene (22). The other clones will be described elsewhere. Sequence analyses indicated that these $\mathrm{RBPJ} \kappa$ clones encode $\mathrm{N}$-terminally truncated polypeptides containing the intact DNA-binding domain. To verify the specificity of the DNA-protein interaction in vivo, we reintroduced into the reporter yeast cells two of the $\mathrm{RBPJ} \kappa$ clones, $6 \mathrm{M} 1$ and $6 \mathrm{~B} 3$. In addition, a plasmid containing the mouse $p 53$ gene, pGAD53m, and the parental vector pACT2 (containing the GAL4 activation domain, GAL4AD) were also introduced into yeast cells as negative controls. As shown in Figure 1B, colonies appeared only in the sectors with yeast cells containing the RBPJ $\kappa$ clones (6M1 and 6B3). Neither mouse p53 nor GAL4AD interacted with the FPIII element. These results demonstrated that GAL4AD $-\mathrm{RBPJ} \kappa$ fusion protein specifically binds to the FPIII element and mediates HIS3 transcription in vivo.

Since the rodent counterpart of human $R B P J \kappa$ gene has not been characterized, we used the human $\mathrm{RBPJ}_{\kappa} \mathrm{cDNA}$ as a probe to screen a rat placental $\lambda \mathrm{gt} 10 \mathrm{cDNA}$ library. The isolated rat $\mathrm{RBPJ} \kappa$ clone, $\mathrm{rRBPJ}_{\kappa}-2 \mathrm{~N}$, contained an open reading frame for a polypeptide of 487 amino acids. Sequence comparison indicated that the isolated clone shares 99\% sequence homology with the murine $\mathrm{RBPJ} \kappa-2 \mathrm{~N}$ at the amino acid level (data not shown), confirming that RBPJK gene is highly conserved among different species. 
A

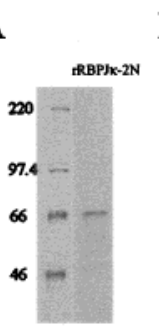

B
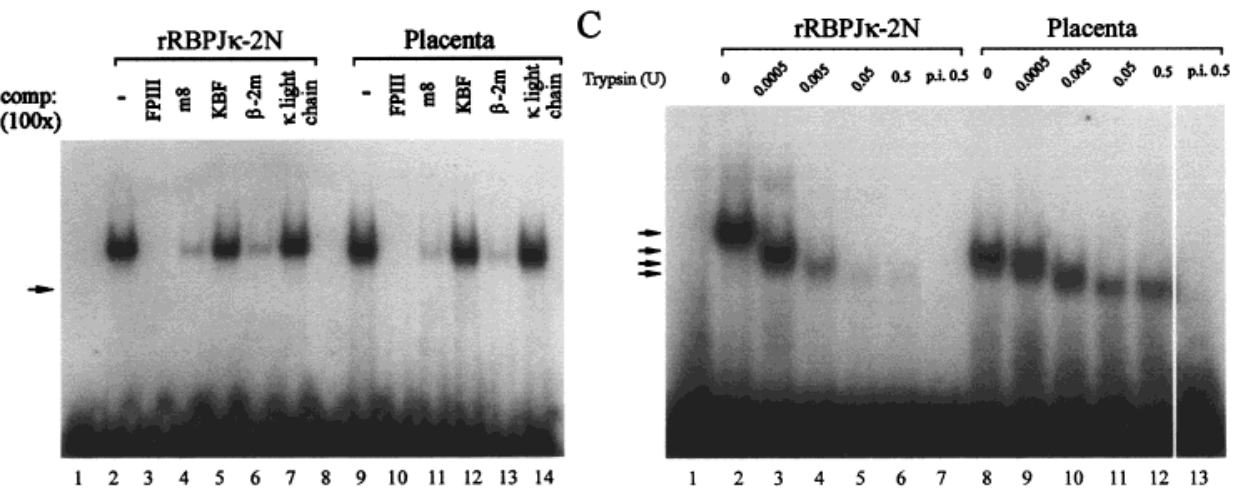

FIGURE 2: Direct binding of $\mathrm{RBPJ} \kappa$ to the FPIII site. (A) Product of in vitro-translated $\mathrm{rRBPJ} \kappa-2 \mathrm{~N}$ was monitored by incorporation of $\left.{ }^{35} \mathrm{~S}\right]$ methionine in the reaction mixtures, and the product was analyzed by SDS-PAGE and autoradiography. Numbers on the left indicate the protein molecular mass markers in kilodaltons. (B) $\mathrm{RBPJ} \kappa$ EMSA with in vitro-translated $\mathrm{rRBPJ} \kappa-2 \mathrm{~N}$ and placental nuclear extracts. In vitro-translated $\mathrm{rRBPJ} \kappa-2 \mathrm{~N}(1 \mu \mathrm{L})$ or $2 \mu \mathrm{g}$ of rat placental nuclear extracts were incubated with radioactively labeled FPIII fragments in EMSA. The DNA-protein complex formed is indicated by the arrow. The identity of the placental FPIII-binding factor was deduced to be an $\mathrm{RBPJ}_{\kappa}$-like factor by competition assay with competitor olignucleotides $\mathrm{m} 8, \mathrm{KBF}, \beta-2 \mathrm{~m}$, and $\mathrm{NF}-\kappa \mathrm{B}$, which are present at 100 -fold excess over the amount of the target DNA. Lanes 1 and 8 are reactions with free probe only. (C) Proteolytic-clipping assay of in vitrotranslated $\mathrm{rRBPJ} \kappa-2 \mathrm{~N}-$ and placental nuclear protein-DNA complexes. EMSA was performed as described for panel (B) except that the protein-DNA complex was challenged with the indicated amount of trypsin (in units) for 10 min on ice before gel electrophoresis. As a control, in vitro-translated $\operatorname{rRBPJ} \kappa-2 \mathrm{~N}$ or placental nuclear protein was preincubated with 0.5 unit of trypsin for 10 min on ice before addition of FPIII probe (p.i. 0.5, lanes 7 and 13). Arrows indicate partially digested complexes. Lane 1 is the reaction with free probe only.

In Vitro Analysis of RBPJK Interacting with the FPIII Element. To investigate whether $\mathrm{RBPJ} \kappa$ directly binds to the FPIII element, we performed electrophoretic mobility shift assay (EMSA) with a ${ }^{32} \mathrm{P}$-labeled FPIII probe and in vitrotranslated $\mathrm{rRBPJ}_{\kappa}-2 \mathrm{~N}$ protein and rat placental nuclear extracts. The estimated molecular mass of $\mathrm{RBPJ}_{\kappa}$ is $60 \mathrm{kDa}$ (23) and the in vitro-translated $\operatorname{rRBPJ} \kappa-2 \mathrm{~N}$ we obtained approximates the predicted size (Figure 2A). As shown in Figure 2B, a DNA-protein complex was observed with both the in vitro-translated $\operatorname{rRBPJ}_{\kappa}-2 \mathrm{~N}$ and the rat placental nuclear extracts (Figure 2B, lanes 2 and 9). Specific proteinDNA interaction was confirmed by the ability of an excess amount of unlabeled FPIII to block complex formation (lanes 3 and 10). To verify that the complex observed in the placental nuclear extracts was formed by $\mathrm{RBPJ} \kappa$, we tried to develop a working antiserum against $\mathrm{rRBPJ}_{\kappa}-2 \mathrm{~N}$ but had no success. We therefore tried to verify the identity of the complex observed in the placental nuclear extracts using two other methods. First, we studied the competition efficiency of a series of oligonucleotides including $\mathrm{m} 8, \mathrm{KBF}, \beta-2 \mathrm{~m}$, and the $\kappa$ light chain in EMSA. The $\mathrm{m} 8$ fragment, originally picked up as the naturally occurring candidate of the $\operatorname{RBPJ}_{\kappa}$ binding sequence from databases, was derived from the 5'flanking region of the Drosophila $m 8$ gene, which is a member of the gene cluster Enhancer of split $[E(s p l)](24$, $25)$. The $\mathrm{KBF}, \beta-2 \mathrm{~m}$, and $\kappa$ light-chain fragments, which all contain the $\mathrm{NF} \kappa \mathrm{B}$ binding sequence, were derived from the promoter/enhancer regions of the mouse major histocompatibility complex (MHC) $\mathrm{H}-2 \mathrm{~K}^{\mathrm{b}}(26)$, the $\beta_{2}$-microglobulin (26), and the immunoglobulin $\kappa$ light chain (27) genes, respectively. Depending on their sequence similarity to FPIII, these three oligonucleotides were expected to have different binding activities to $\mathrm{RBPJ} \kappa$ and were purposely picked to be used as controls. As shown in Figure 2B, in both of the complexes formed with $\mathrm{rRBPJ} \kappa-2 \mathrm{~N}$ and the placental nuclear extracts, $\mathrm{m} 8$ and $\beta-2 \mathrm{~m}$ had a higher potency than KBF and the $\kappa$ light chain in blocking complex formation (Figure 2B, lanes 4, 6, 11, and 13). Second, we performed proteolyticclipping band-shift assays using both protein sources. After the DNA-protein complex formation, we treated the complexes with increasing amounts of trypsin. We observed two similar ladders of complexes of decreasing molecular weights from the two protein sources when the amount of trypsin was increased from 0.0005 to 0.5 unit (Figure 2C). The results suggested that the placental nuclear factor and $\operatorname{rRBPJ} \kappa-2 \mathrm{~N}$ have a similar conformation so that similar trypsin digestion patterns were observed. As a control, preincubation of proteins with 0.5 unit of trypsin completely abolished complex formation (Figure 2C, lanes 7 and 13). Similar results were obtained with chymotrypsin digestion (data not shown). It is not clear why we did not observe discrete bands resulted from partially digested $\mathrm{RBPJ}_{\kappa}-\mathrm{FPIII}$ complex. However, Brou et al. (28) demonstrated that the essential DNA-binding domain of the human $\mathrm{RBPJ}_{\kappa} \kappa$ isoform, RBP3, encompasses the entire residues 7-435 region of the 486-amino acid polypeptide. Therefore, cleavage in the small regions outside the DNA-binding domain would likely result in only small differences in mobility of the complexes and might not be well resolved in our gel analysis (Figure 2C, lanes 3, 4, 9, and 10, arrows). Taken together, our data suggested that $\mathrm{RBPJ}_{\kappa}$ is a constitutive nuclear factor binding to the FPIII site of the $r n C G M 3$ promoter in placenta.

To identify more specifically the nucleotides in the FPIII region important for $\operatorname{rRBPJ} \kappa-2 \mathrm{~N}$ binding, we performed competition experiments using in vitro-translated $\mathrm{rRBPJ}_{\kappa}$ $2 \mathrm{~N}$ and a series of mutant oligonucleotides to compete with the target DNA (Table 1). Mutant oligonucleotides M34, M34A, M56, and M78 did not compete efficiently with FPIII for $\operatorname{rRBPJ}_{\kappa}$-2N (Table 1, data not shown). These results indicated that the sequence CTGGGA in the FPIII region is the core binding sequence for $\operatorname{rRBPJ} \kappa-2 \mathrm{~N}$.

Effect of RBPJK and Notch on FPIII-Reporter Constructs. We next investigated the effect of $\mathrm{RBPJ}_{\kappa}$ on the expression of the FPIII-containing promoter construct $\mathrm{p}$ (FPIII) ${ }_{6}$ SV40CAT, which contains six copies of FPIII site inserted in front of the SV40 promoter and the bacterial CAT gene coding sequence. Since $\mathrm{RBPJ} \kappa$ is a downstream effector in the Notch signaling pathway, we examined $C A T$ expression in the 


\begin{tabular}{|c|c|c|c|c|}
\hline construct & sequence & $\mathrm{rRBPJ}_{\kappa}-2 \mathrm{~N}$ & NotchIC & fold induction \\
\hline \multirow[t]{3}{*}{$\mathrm{p}(\mathrm{FPIII})_{6} \mathrm{SV} 40 \mathrm{CAT}$} & (GCCTGGGAAAAAACTC) & + & - & $0.37 \pm 0.03$ \\
\hline & & + & + & $1.71 \pm 0.20$ \\
\hline & & - & + & $24.21 \pm 1.48$ \\
\hline $\mathrm{p}$ (FPIIIM34) ${ }_{5}$ SV40CAT & (GCTAGGGAAAAAACTC) & - & + & $0.97 \pm 0.01$ \\
\hline $\mathrm{p}\left(\right.$ FPIIIM56) ${ }_{4}$ SV40CAT & 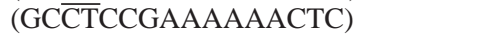 & - & + & $0.81 \pm 0.08$ \\
\hline $\mathrm{p}(\mathrm{FPI})_{6} \mathrm{SV} 40 \mathrm{CAT}$ & (TGTCATCCCTGGGATGAGTGTT) & - & + & $9.90 \pm 0.90$ \\
\hline $\mathrm{p}(\mathrm{FPIM} 34 \mathrm{~A})_{6} \mathrm{SV} 40 \mathrm{CAT}$ & (TGTCATCCAGGGGATGAGTGTT) & - & + & $1.12 \pm 0.23$ \\
\hline
\end{tabular}

${ }^{a}$ COS- 1 cells were transfected with $3 \mu \mathrm{g}$ of FPIII- or FPI-reporter construct and $3 \mu \mathrm{g}$ of pCMVrRBPJ $\kappa-2 \mathrm{~N}$ or $1 \mu \mathrm{g}$ of mNotchIC or both. Cells were harvested as described under Materials and Methods. Specific CAT activities directed by p(FPIII) $)_{6}$ SV40CAT, p(FPIIIM34) 5 SV40CAT, p(FPIIIM56) ${ }_{4}$ SV40CAT, $p$ (FPI) $)_{6}$ SV40CAT, and p(FPIM34A) 6 SV40CAT were $0.086 \pm 0.001,0.101 \pm 0.008,0.11 \pm 0.006,0.07 \pm 0.004$, and $0.115 \pm 0.008 \mathrm{nmol} \mathrm{min}^{-1}$ (mg of protein) ${ }^{-1}$, respectively. Fold induction was calculated relative to the CAT expression observed in the absence of $\mathrm{rRBPJ} \kappa-2 \mathrm{~N}$ or $\mathrm{mNotchIC}$ expression plasmids for individual reporter plasmids. Mean values $\pm \mathrm{SEM}$ from three independent transfection experiments are provided.

A

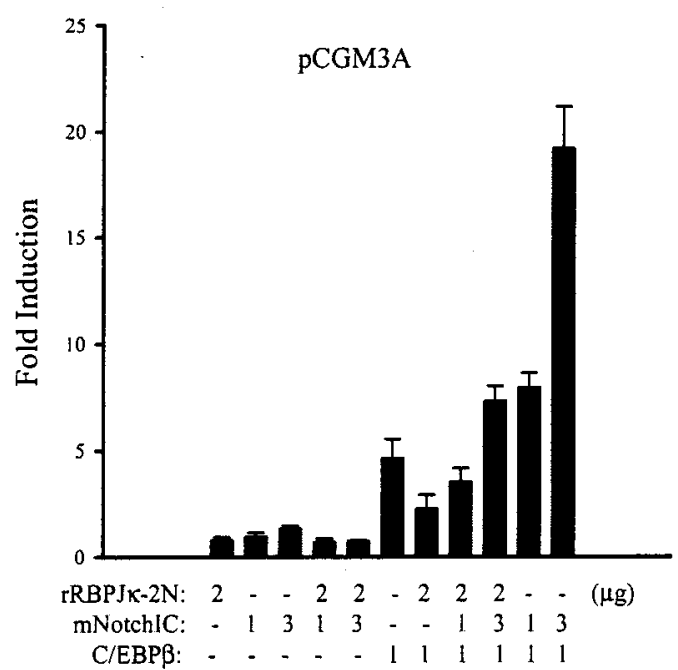

B

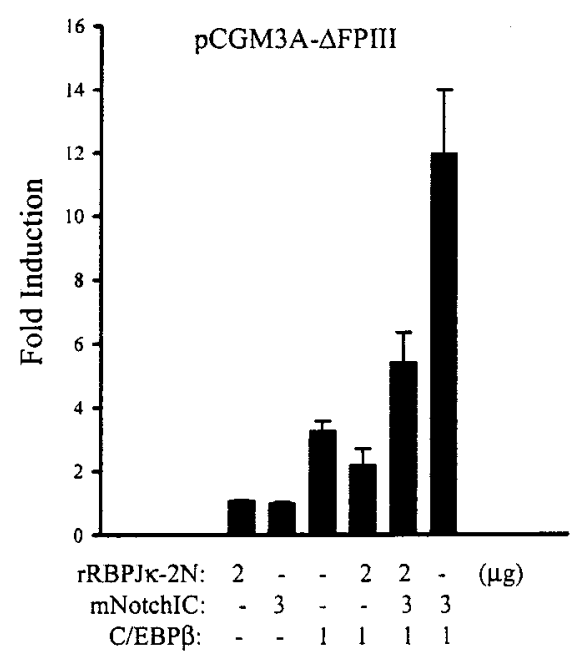

FIGURE 3: Functional interaction between mNotchIC- and C/EBP $\beta$-stimulated luciferase expression directed by the $r n C G M 3$ promoter construct. (A) The $r n C G M 3$ promoter-luciferase construct, pCGM3A, containing FPI, -II, and -III sites was generated in the promoterless and enhancerless pGL3-Basic plasmid as described under Materials and Methods. COS-7 cells were transfected with $3 \mu \mathrm{g}$ of pCGM3A alone or plus an expression plasmid encoding either $\operatorname{rRBPJ} \kappa-2 \mathrm{~N}, \mathrm{C} / \mathrm{EBP} \beta$, or mNotchIC or various combinations of these plasmids. The amounts (in micrograms) of expression plasmids used in each transfection are listed along the $x$-axis. Fold induction was calculated relative to the luciferase expression observed for pCGM3A alone. Mean values and SEM obtained from four independent transfection experiments are plotted. (B) Transient expression assays with an FPIII-deleted construct, pCGM3A- $\Delta$ FPIII. The scheme for transfection was the same as described for panel (A). Mean values and SEM obtained from four independent transfection experiments are plotted. The luciferase activities directed by pCGM3A and pCGM3A- $\Delta$ FPIII were $825.75 \pm 44.14$ and $498.33 \pm 29.06$ relative light units (RLU)/ $\mu \mathrm{g}$ of protein, respectively.

presence of $\operatorname{rRBPJ} \kappa-2 \mathrm{~N}$ or the active intracellular domain of Notch or both. The construct mNotchIC contains the active intracellular domain initiating at the $5^{\prime}$ nuclear localization signal (NLS; TKKFRFEE) followed by the CDC10 domain and terminates at the $3^{\prime}$ NLS (KGWLLDSS). As shown in Table 2, the CAT level in the presence of exogenous $\operatorname{rRBPJ}_{\kappa}$ $2 \mathrm{~N}$ was reduced to $37 \%$ of the control. However, this repression by $\operatorname{rRBPJ} \kappa-2 \mathrm{~N}$ was counteracted by NotchIC. The stimulatory effect of NotchIC without $\operatorname{rRBPJ}_{\kappa}-2 \mathrm{~N}$ was even more conspicuous and reached 24.21-fold over the control. The $\operatorname{RBPJ}_{\kappa}$ core sequence was required to achieve the stimulation effect observed with NotchIC since CAT levels directed by $\mathrm{p}$ (FPIIIM34) $)_{5}$ SV40CAT and p(FPIIIM56) ${ }_{4}$ SV40CAT, which contain the M34 and M56 mutations in the RBPJ $\kappa$ core sequence in the FPIII site (Table 1 ), were only 0.97 - and 0.81-fold over the control, respectively (Table 2). These results suggested that Notch and $\mathrm{RBPJ} \kappa$ may be involved in $r n C G M 3$ expression through the FPIII site.
Notch Enhances the Transcriptional Activation of C/EBP $\beta$ on the Natural rnCGM3 Promoter. Earlier studies on the $r n C G M 3$ promoter indicated that $\mathrm{C} / \mathrm{EBP} \beta$ is a positive regulator that binds to the FPII site (14). Accordingly, interplay among $\mathrm{C} / \mathrm{EBP} \beta, \operatorname{RBPJ} \kappa$ and Notch may be involved in the modulation of $r n C G M 3$ expression. To test this hypothesis, we placed nucleotides -326 to -33 of the 5'flanking region of $r n C G M 3$ gene, which includes all three FP sites, in front of the luciferase gene in the plasmid pGL3Basic (see Materials and Methods). The resultant $r n C G M 3$ promoter construct was named pCGM3A. We examined the luciferase activities after cotransfecting pCGM3A with the plasmids encoding $\mathrm{C} / \mathrm{EBP} \beta, \operatorname{rRBPJ} \kappa-2 \mathrm{~N}$, or NotchIC into COS-7 cells, which are known for a low level of endogenous $\mathrm{RBPJ}_{\kappa}(29)$. As shown in Figure $3 \mathrm{~A}$, neither $\operatorname{rRBPJ} \kappa-2 \mathrm{~N}$ nor NotchIC significantly increased luciferase activity in the pCGM3A transfected COS-7 cells. Both proteins together also did not have any effect, whereas $\mathrm{C} / \mathrm{EBP} \beta$ increased 
luciferase activity by 4.6 -fold. The transactivation by $\mathrm{C} / \mathrm{EBP} \beta$ was decreased to 2.2-fold when it was cotransfected with 2 $\mu \mathrm{g}$ of the plasmid encoding $\operatorname{rRBPJ}_{\kappa}-2 \mathrm{~N}$. However, this repression was counteracted by mNotchIC in a dosedependent manner. Interestingly, transactivation by $\mathrm{C} / \mathrm{EBP} \beta$ was further enhanced to 8.0- or 19.2-fold with 1 or $3 \mu \mathrm{g}$ of mNotchIC (Figure 3A). To examine if the stimulatory effect of NotchIC depends on the FPIII element, we cotransfected pCGM3A- $\triangle$ FPIII, which is an FPIII-deleted pCGM3A construct, with plasmids encoding $\mathrm{C} / \mathrm{EBP} \beta, \operatorname{rRBPJ} \kappa-2 \mathrm{~N}$, or NotchIC. To our surprise, a similar profile of promoter activities was observed (Figure 3B), only the stimulation by NotchIC was lower than in the full-length promoter (11.96fold versus 19.21-fold). These data suggested that there might be another functional $\operatorname{RBPJ}_{\kappa}$ site, which is responsive to NotchIC, present in the native $r n C G M 3$ promoter.

We inspected the $r n C G M 3$ promoter region from nucleotides -326 to -33 and identified another $\mathrm{RBPJ}_{\kappa}$ core sequence (CTGGGA) within the FPI site (Figure 1A, FPI, underlined). To test whether this FPI- $\mathrm{RBPJ} \kappa$ core sequence contributes to the NotchIC activation on the pCGM3A$\Delta$ FPIII promoter construct mentioned above, we first performed transient expression assays with the $\mathrm{p}(\mathrm{FPI})_{6} \mathrm{SV} 40 \mathrm{CAT}$ or the $\mathrm{p}(\mathrm{FPIM} 34 \mathrm{~A})_{6}$ SV40CAT reporter plasmid and mNotchIC. The $\mathrm{p}(\mathrm{FPI})_{6} \mathrm{SV} 40 \mathrm{CAT}$ and $\mathrm{p}$ (FPIM34A) ${ }_{6} \mathrm{SV} 40 \mathrm{CAT}$ constructs contain six copies of the FPI site and six copies of the FPIM34A mutant site (Table 2), respectively, inserted in front of the SV40 promoter and the bacterial CAT gene coding sequence. As shown in Table 2, CAT levels directed by $\mathrm{p}(\mathrm{FPI})_{6}$ SV40CAT but not $\mathrm{p}$ (FPIM34A) ${ }_{6}$ SV40CAT were stimulated by mNotchIC (9.9- versus 1.1 -fold). These data suggested that the $\mathrm{RBPJ}_{\kappa}$ core sequence in the FPI site was responsible for NotchIC transactivation on the SV40 promoter. EMSA also revealed a specific binding between FPI and the in vitro-translated $\operatorname{rRBPJ} \kappa-2 \mathrm{~N}$ (data not shown).

We next verified the effect of the FPIII RBPJ $\kappa$-binding site on the $r n C G M 3$ promoter without the contribution from the FPI site. We made the construct pCGM3B, which consists of the $r n C G M 3$ promoter region of nucleotides -283 to -33 , containing the FPII ( -263 to -233$)$ and the FPIII $(-108$ to -93 ) sites, fused to the luciferase reporter gene. As shown in Figure 4, similar to results observed with pCGM3A, the luciferase levels directed by pCGM3B were positively regulated by $\mathrm{C} / \mathrm{EBP} \beta$, repressed by $\operatorname{rRBPJ} \kappa-2 \mathrm{~N}$, and further enhanced by NotchIC (Figure 4, left). Furthermore, this positive effect of NotchIC was not observed with pCGM3BFPIIIM34A (Figure 4, middle), indicating that the FPIII $\mathrm{RBPJ}_{\kappa}$-binding site was also required for the transcriptional activation of NotchIC. To confirm that the stimulatory effect of NotchIC was mediated only through the RBPJ $\kappa$-binding sites in FPI and FPIII, we further introduced the M34A mutation into the $\mathrm{RBPJ}_{\kappa}$ core sequence (CTGGGA to AGGGGA, Tables 1 and 2) in both sites in pCGM3A and the resultant reporter construct pCGM3A-FPI\&IIIM34A was used for transient expression assays. As shown in the right panel of Figure 4, the stimulatory effect of NotchIC was completely abolished. Taken together, both $\mathrm{RBPJ}_{\kappa}$-binding sites in FPI and FPIII contributed to the NotchIC enhancement of the $r n C G M 3$ promoter activities transactivated by $\mathrm{C} / \mathrm{EBP} \beta$. These results also indicate a functional interaction between $\mathrm{C} / \mathrm{EBP} \beta$ and NotchIC.

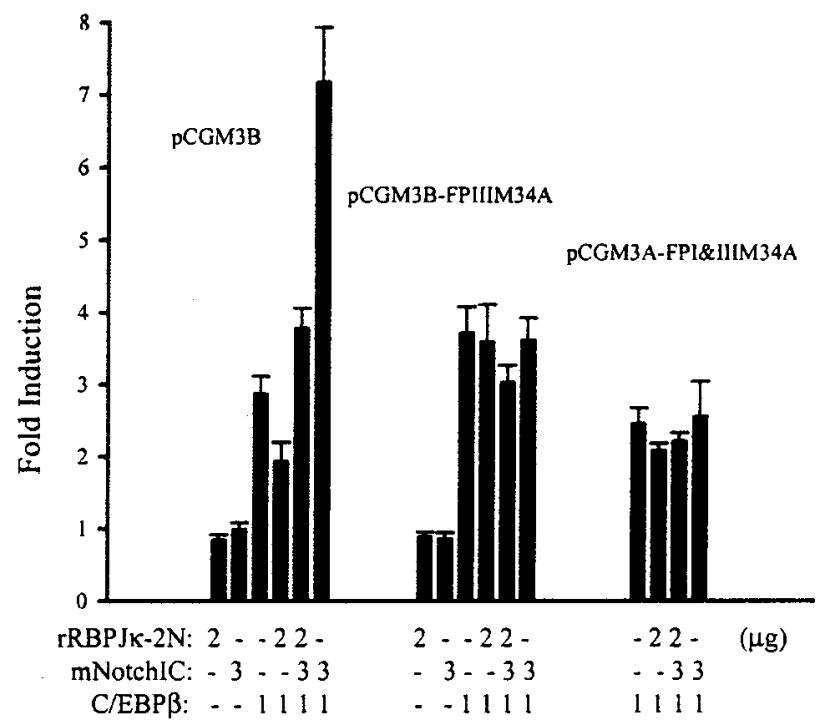

FIGURE 4: Both FPIII and FPI RBPJ $\kappa$-binding sites are functional for supporting the stimulatory effect of NotchIC. COS-7 cells were transfected with $3 \mu \mathrm{g}$ of the various promoter constructs, as indicated above each group of data, or plus the indicated amount of expression plasmid containing various combinations of $\operatorname{rRBPJ} \kappa$ $2 \mathrm{~N}, \mathrm{C} / \mathrm{EBP} \beta$, or mNotchIC. Mean values and SEM obtained from three independent transfection experiments are plotted. The luciferase activities directed by pCGM3B, pCGM3B-FPIIIM34A, and pCGM3A-FPI\&IIIM34A were $496.5 \pm 143.72,267.83 \pm$ 44.87 , and $423.02 \pm 35.9 \mathrm{RLU} / \mu \mathrm{g}$ of protein, respectively.

\section{DISCUSSION}

We performed a yeast one-hybrid screening and identified $\mathrm{RBPJ}_{\kappa}$ as a nuclear factor recognizing the FPIII site in the $r n C G M 3$ promoter. Several lines of evidence support that expression of $r n C G M 3$ is mediated by $\mathrm{RBPJ}_{\kappa}$ in the Notch signaling pathway. First, $\mathrm{rRBPJ}_{\kappa}-2 \mathrm{~N}$ repressed expression of the heterologous SV40 promoter via FPIII and this repression was counteracted by NotchIC (Table 2). Second, the $\mathrm{RBPJ}_{\kappa}$ core sequence (CTGGGA) in the FPIII and FPI sites was required for NotchIC to transactivate the SV40 promoter. This positive effect of NotchIC was abolished when residues in the $\mathrm{RBPJ} \kappa$ core sequence were altered. It is unlikely that ligation of multiple copies of FPIII and FPI oligonucleotides fortuitously generated $\mathrm{RBPJ}_{\kappa}$-binding sites in our reporter constructs because the mutant constructs also contain the same flanking sequences. Third, transcriptional activation by $\mathrm{C} / \mathrm{EBP} \beta$ on the $r n C G M 3$ promoter was repressed by $\operatorname{rRBPJ} \kappa-2 \mathrm{~N}$ but significantly enhanced by NotchIC. Fourth, both the FPI and FPIII RBPJ $\kappa$-binding sites in the $r n C G M 3$ promoter were functional in the Notch signaling pathway because the enhancement effect of NotchIC on $\mathrm{C} / \mathrm{EBP} \beta$ could be accomplished by either site, and when both sites were mutated, the enhancement effect was abolished. Taken together, we propose that expression of the $r n C G M 3$ gene is upregulated by $\mathrm{C} / \mathrm{EBP} \beta$ via the FPII site and by $\mathrm{RBPJ}_{\kappa} /$ Notch via the FPI and FPIII sites. This also suggests that $r n C G M 3$ is likely a target gene of the Notch signaling pathway, which may provide another mechanism to control PSG expression in the placenta in addition to regulations by $\mathrm{C} / \mathrm{EBP} \beta$.

$\mathrm{RBPJ} \kappa$ is identical to the cellular factor CBF1 that binds to the Epstein-Barr virus (EBV) $C$ promoter (30) and the nuclear factor KBF2 that binds to the enhancer of mouse 
MHC class I genes (28). The Drosophila homologue of $R B P J \kappa$ gene is the Suppressor of Hairless $[\mathrm{Su}(H)]$ gene, which is involved in the peripheral nervous system development $(31,32)$. RBPJ $\kappa$ can associate with a variety of proteins including the Drosophila hairless protein (28), the EBV nuclear antigen 2 (EBNA2) (33-36), the intracellular domain of Notch protein (NotchIC) $(37,38)$, and a recently isolated LIM protein, KyoT2 (39). Neither EBNA2 nor NotchIC binds directly to DNA. Upon association with $\mathrm{RBPJ} \kappa$, $\mathrm{RBPJ}_{\kappa} / \mathrm{EBNA} 2$ and $\mathrm{RBPJ} /$ /NotchIC complexes activate target genes through the $\mathrm{RBPJ} \kappa$ site. In addition, $\mathrm{RBPJ} \kappa$ interacts with two transcriptional coactivators, $\mathrm{dTAF}_{\mathrm{II}} 110$ (a subunit of TFIID) and TFIIA, to repress transcription (40). Recently, Hsieh et al. (41) reported another RBPJ $\kappa$-interacting protein called CIR (CBF1 interacting corepressor), which interacts with a histone deacetylase (HDAC) and another corepressor, SAP30. Therefore, association between $\mathrm{RBPJ}_{\kappa}$ and CIR may further recruit HDAC and other corepressor to modify chromatin structure and diminish transcriptional activities (41).

The promoter of the mouse Hairy enhancer of split (HES1) gene contains two adjacent $\mathrm{RBPJ} \kappa$-binding sites centered at nucleotide -81 and -67 , respectively, from the transcription start site (42). However, the two sites are not functionally equivalent because a mutation in the distal $\operatorname{RBPJ}_{\kappa}$ site abolishes activation by NotchIC, whereas a mutation in the proximal site does not affect it (43). In the present study, we characterized, in the $r n C G M 3$ promoter, two separate $\mathrm{RBPJ} \kappa$-binding sites that are upstream and downstream, respectively, from the transcription start site. Unlike the two $\mathrm{RBPJ}_{\kappa}$-binding sites in $H E S$ - 1 , the two $\mathrm{RBPJ}_{\kappa}$-binding sites in $r n C G M 3$ are functionally equivalent because mutations in either site do not abolish the positive effect of NotchIC.

$\operatorname{rRBPJ} \kappa-2 \mathrm{~N}$ repressed the transcriptional activation of $\mathrm{C} / \mathrm{EBP} \beta$ on the $r n C G M 3$ promoter. It is possible that $\operatorname{rRBPJ} \kappa-2 \mathrm{~N}$ associates with transcriptional coactivators such as TFIIA, which interferes with the interaction between $\mathrm{C} / \mathrm{EBP} \beta$ and the basal transcriptional machinery. $\operatorname{rRBPJ} \kappa_{-}-$ $2 \mathrm{~N}$ could also interact with protein like CIR, which results in chromatin modification and reduces the transcriptional activation by $\mathrm{C} / \mathrm{EBP} \beta$. These $\mathrm{RBPJ} \kappa$-associated factors may be displaced by NotchIC in mNotchIC-transfected cells. The resultant positive regulator complex $\mathrm{RBPJ} \kappa /$ NotchIC further enhances the transcriptional activation of $\mathrm{C} / \mathrm{EBP} \beta$ on the rnCGM3 promoter.

Neither $\operatorname{rRBPJ} \kappa-2 \mathrm{~N}$, NotchIC, nor both proteins together had a significant effect on the expression of a native $r n C G M 3$ promoter. Instead, the regulatory functions of $\operatorname{rRBPJ} \kappa-2 \mathrm{~N}$ and NotchIC were manifested in the presence of the FPIIbinding factor $\mathrm{C} / \mathrm{EBP} \beta$. This phenomenon is reminiscent of the context-dependent regulation of the T-cell receptor (TCR) $\alpha$ enhancer by LEF-1/TCF- $1 \alpha$. In this case, a specific arrangement and occupancy of the CRE- and TCF-2 protein binding sites surrounding the LEF-1/TCF- $1 \alpha$ binding site is required for the transcriptional activation of LEF-1/TCF- $1 \alpha$ (44). It is possible that preoccupancy of the FPII site by $\mathrm{C} / \mathrm{EBP} \beta$ in the $r n C G M 3$ promoter provides a permissive condition for an effective Notch signaling pathway. We have performed yeast and mammalian two-hybrid assays $(45,46)$ using C/EBP $\beta$ and NotchIC and failed to detect any physical interaction between the two factors (data not shown). Additional studies are required to elucidate this functional interaction between $\mathrm{C} / \mathrm{EBP} \beta$ and the Notch signaling pathway.

Interestingly, we observed that the stimulatory effect of NotchIC is stronger in the absence of exogenous $r R B P J \kappa-$ $2 \mathrm{~N}$. However, it has been shown recently that the transactivation activity of NotchIC is completely dependent on $\operatorname{RBPJ}_{\kappa}$ because the activity was not observed in an $\mathrm{RBPJ}_{\kappa}$ null cell line (47). It is possible that the endogenous level of $\mathrm{RBPJ} \kappa$ in COS-7 is sufficient for NotchIC to enhance the transcriptional activity of $\mathrm{C} / \mathrm{EBP} \beta$. This enhancement effect of NotchIC may depend on the ratio between the amounts of NotchIC and RBPJ $\kappa$ in the nucleus. An excess amount of exogenous $\mathrm{RBPJ}_{\kappa}$ may reduce this enhancement effect.

We have used the COS7 cell line instead of a placental cell line. A placental cell line may provide a more natural condition for transient expression assays. However, sometimes the specific effects of transfected expression vectors are complicated by the existence of endogenous proteins. In comparison, in a nonplacental cell line, it may be easier to observe specific effects of the transfected expression vectors. The COS7 cells have been widely used in Notch and RBPJ $\kappa$ studies $(39,48,49)$. In particular, this cell line contains a low level of endogenous $\operatorname{RBPJ} \kappa$, which is critical to our characterization of the specific role of $\mathrm{RBPJ} \kappa$. Moreover, the observation that $\mathrm{C} / \mathrm{EBP} \beta$ stimulated $r n C G M 3$ promoter activity in COS7 cells is similar to our previous observation in a human placental cell line, HPA1 (14). Therefore, the COS7 cell line should be a valid starting material to study the interplay between $\mathrm{C} / \mathrm{EBP} \beta$, NotchIC, and $\mathrm{RBPJ} \kappa$.

Using transient transfection of promoter-reporter constructs and EMSA, we have obtained a basic framework of interaction between the three factors. However, these simpler experimental systems have their limitations. For example, the chromosomal organization of $r n C G M 3$ gene in the living cell may play a potential role in gene activation. It has been shown that chromatin remodeling regulates the yeast $\mathrm{PHO5}$ and the mouse mammary tumor virus promoter activities (50, 51). Given that the enhancement effect of NotchIC on $\mathrm{C} / \mathrm{EBP} \beta$ is context-dependent with the naked DNA construct, it is not clear whether these factors are accessible to their binding sites in the chromosomal context of $r n C G M 3$. This issue deserves more attention in future studies.

One of the phenotypes in $\operatorname{RBPJ}_{\kappa}$ knockout mice is placental failure (52). It will be interesting to investigate whether silencing of the RBPJ $\kappa /$ Notch-regulated genes, e.g., PSG genes, contributes to the abnormal placental development in $\mathrm{RBPJ}_{\kappa}$ knockout mice. In addition, Nakayama et al. (53) reported that Notch is involved in trophoblast differentiation. Since PSGs are expressed in the giant cell/ spongiotrophoblast of the rodent placenta, additional investigation is warranted to determine whether $r n C G M 3$ expression is correlated with the Notch-mediated trophoblast differentiation.

\section{ACKNOWLEDGMENT}

We thank Dr. R. Kopan for gifts of cDNA for mNotchIC, Dr. Hsou-min Li for critical reading of the manuscript, and Yung-kang Lee for technical support.

\section{REFERENCES}

1. Chou, J. Y., and Plouzek, C. A. (1992) Semin. Reprod. Endocrinol. 10, 116-126. 
2. Lin, T. M., Halbert, S. P., and Spellacy, W. N. (1974) J. Clin. Invest. 54, 576-582.

3. MacDonald, D. J., Scott, J. M., Gemmell, R. S., and Mack, D. S. (1983) Am. J. Obstet. Gynecol. 147, 430-436.

4. Mantzavinos, T., Phocas, I., Chrelias, H., Sarandakou, A., and Zourlas, P. A. (1991) Eur. J. Obstet. Gynecol. Reprod. Biol. 39, $117-122$.

5. Masson, G. M., Anthony, F., and Wilson, M. S. (1983) Br. J. Obstet. Gynaecol. 90, 146-149.

6. Tamsen, L., Johansson, S. G., and Axelsson, O. (1983) J. Perinat. Med. 11, 19-25.

7. Bohn, H., and Weinmann, E. (1974) Arch. Gynakol. 217, 209218.

8. Hau, J., Gidley-Baird, A. A., Westergaard, J. G., and Teisner, B. (1985) Biomed. Biochim. Acta 44, 1255-1259.

9. Rutherfurd, K. J., Chou, J. Y., and Mansfield, B. C. (1995) Mol. Endocrinol. 9, 1297-1305.

10. Rebstock, S., Lucas, K., Thompson, J. A., and Zimmermann, W. (1990) J. Biol. Chem. 265, 7872-7879.

11. Chen, H., Chen, C. L., and Chou, J. Y. (1994) Biochemistry 33, 9615-9626.

12. Chen, H., Plouzek, C. A., Liu, J. L., Chen, C. L., and Chou, J. Y. (1992) DNA Cell Biol. 11, 139-148.

13. Kromer, B., Finkenzeller, D., Wessels, J., Dveksler, G., Thompson, J., and Zimmermann, W. (1996) Eur. J. Biochem. 242, 280-287.

14. Chen, H., Lin, B., Chen, C. L., Johnson, P. F., and Chou, J. Y. (1995) DNA Cell Biol. 14, 681-688.

15. Wang, M. M., and Reed, R. R. (1993) Nature 364, 121-126.

16. Ausubel, F. M., Brent, R., Kingston, R. E., Moore, D. D., Seidman, J. G., Smith, J. A., and Struhl, K. (1992) Current Protocols in Molecular Biology, Greene Publishing Associates/ Wiley-Interscience, New York.

17. Williams, S. C., Cantwell, C. A., and Johnson, P. F. (1991) Genes Dev. 5, 1553-1567.

18. Kopan, R., Schroeter, E. H., Weintraub, H., and Nye, J. S. (1996) Proc. Natl. Acad. Sci. U.S.A. 93, 1683-1688.

19. Ohlsson, H., and Edlund, T. (1986) Cell 45, 35-44.

20. Laux, G., Adam, B., Strobl, L. J., and Moreau-Gachelin, F. (1994) EMBO J. 13, 5624-5632.

21. Fordis, C. M., and Howard, B. H. (1987) Methods Enzymol. $151,382-397$.

22. Amakawa, R., Jing, W., Ozawa, K., Matsunami, N., Hamaguchi, Y., Matsuda, F., Kawaichi, M., and Honjo, T. (1993) Genomics 17, 306-315.

23. Matsunami, N., Hamaguchi, Y., Yamamoto, Y., Kuze, K., Kangawa, K., Matsuo, H., Kawaichi, M., and Honjo, T. (1989) Nature 342, 934-937.

24. Klambt, C., Knust, E., Tietze, K., and Campos-Ortega, J. A. (1989) EMBO J. 8, 203-210.

25. Tun, T., Hamaguchi, Y., Matsunami, N., Furukawa, T., Honjo, T., and Kawaichi, M. (1994) Nucleic Acids Res. 22, 965971.

26. Israel, A., Kimura, A., Kieran, M., Yano, O., Kanellopoulos, J., Le Bail, O., and Kourilsky, P. (1987) Proc. Natl. Acad. Sci. U.S.A. 84, 2653-2657.

27. Sen, R., and Baltimore, D. (1986) Cell 46, 705-716.

28. Brou, C., Logeat, F., Lecourtois, M., Vandekerckhove, J., Kourilsky, P., Schweisguth, F., and Israel, A. (1994) Genes Dev. 8, 2491-2503.
29. Hamaguchi, Y., Yamamoto, Y., Iwanari, H., Maruyama, S., Furukawa, T., Matsunami, N., and Honjo, T. (1992) J. Biochem. (Tokyo) 112, 314-320.

30. Dou, S., Zeng, X., Cortes, P., Erdjument-Bromage, H., Tempst, P., Honjo, T., and Vales, L. D. (1994) Mol. Cell Biol. 14, 3310-3319.

31. Furukawa, T., Maruyama, S., Kawaichi, M., and Honjo, T. (1992) Cell 69, 1191-1197.

32. Schweisguth, F., and Posakony, J. W. (1992) Cell 69, 11991212.

33. Grossman, S. R., Johannsen, E., Tong, X., Yalamanchili, R., and Kieff, E. (1994) Proc. Natl. Acad. Sci. U.S.A. 91, 75687572 .

34. Henkel, T., Ling, P. D., Hayward, S. D., and Peterson, M. G. (1994) Science 265, 92-95.

35. Waltzer, L., Logeat, F., Brou, C., Israel, A., Sergeant, A., and Manet, E. (1994) EMBO J. 13, 5633-5638.

36. Zimber-Strobl, U., Strobl, L. J., Meitinger, C., Hinrichs, R., Sakai, T., Furukawa, T., Honjo, T., and Bornkamm, G. W. (1994) EMBO J. 13, 4973-4982.

37. Lu, F. M., and Lux, S. E. (1996) Proc. Natl. Acad. Sci. U.S.A. 93, 5663-5667.

38. Tamura, K., Taniguchi, Y., Minoguchi, S., Sakai, T., Tun, T., Furukawa, T., and Honjo, T. (1995) Curr. Biol. 5, 1416-1423.

39. Taniguchi, Y., Furukawa, T., Tun, T., Han, H., and Honjo, T. (1998) Mol. Cell Biol. 18, 644-654.

40. Olave, I., Reinberg, D., and Vales, L. D. (1998) Genes Dev. 12, 1621-1637.

41. Hsieh, J. J., Zhou, S., Chen, L., Young, D. B., and Hayward, S. D. (1999) Proc. Natl. Acad. Sci. U.S.A. 96, 23-28.

42. Takebayashi, K., Sasai, Y., Sakai, Y., Watanabe, T., Nakanishi, S., and Kageyama, R. (1994) J. Biol. Chem. 269, 5150-5156.

43. Jarriault, S., Brou, C., Logeat, F., Schroeter, E. H., Kopan, R., and Israel, A. (1995) Nature 377, 355-358.

44. Carlsson, P., Waterman, M. L., and Jones, K. A. (1993) Genes Dev. 7, 2418-2430.

45. Chien, C. T., Bartel, P. L., Sternglanz, R., and Fields, S. (1991) Proc. Natl. Acad. Sci. U.S.A. 88, 9578-9582.

46. Fearon, E. R., Finkel, T., Gillison, M. L., Kennedy, S. P., Casella, J. F., Tomaselli, G. F., Morrow, J. S., and Van-Dang, C. (1992) Proc. Natl. Acad. Sci. U.S.A. 89, 7958-7962.

47. Kato, H., Taniguchi, Y., Kurooka, H., Minoguchi, S., Sakai, T., Nomura-Okazaki S., Tamura, K., and Honjo, T. (1997) Development 124, 4133-4141.

48. Kannabiran, C., Zeng, X., and Vales, L. D. (1997) Mol. Cell. Biol. 17, 1-9.

49. Oswald, F., Liptay, S., Adler, G., and Schmid, R. M. (1998) Mol. Cell. Biol. 18, 2077-2088.

50. Fascher, K. D., Schmitz, J., and Horz, W. (1993) J. Mol. Biol. $231,658-667$.

51. Lee, H. L., and Archer, T. K. (1994) Mol. Cell. Biol. 14, 3241.

52. Oka, C., Nakano, T., Wakeham, A., de la Pompa, J. L., Mori, C., Sakai, T., Okazaki, S., Kawaichi, M., Shiota, K., Mak, T. W., and Honjo, T. (1995) Development 121, 3291-3301.

53. Nakayama, H., Liu, Y., Stifani, S., and Cross, J. C. (1997) Dev. Genet. 21, 21-30.

BI991786K 